\title{
LA CONSTITUCIÓN Y EL PROBLEMA DE LA AGENCIA EN LAS SOCIEDADES DE CAPITAL CONCENTRADO DESDE EL ANÁLISIS ECONÓMICO DEL DERECHO
}

\author{
Javier Francisco Franco Mongua** \\ Jaime Alberto Manrique Rodríguez ${ }^{* * *}$
}

Fecha de recepción: 14 de julio de 2014

Fecha de evaluación: 24 de febrero de 2015

Fecha de aprobación: 23 de junio de 2015

Artículo de reflexión

DOI:http://dx.doi.org/10.18359/dere.938

Forma de citación: Franco, J. \& Manrique, J. (2015). La constitución y el problema de la agencia en las sociedades de capital concentrado desde el análisis económico del derecho. Revista Prolegómenos Derechos y Valores, 18, 36, 135-152. DOI:http://dx.doi.org/10.18359/dere.938

\section{Resumen}

Las normas jurídicas en materia societaria regulan la estructura de las sociedades comerciales de capital concentrado y las sociedades comerciales de capital difuso, de las cuales se desprenden problemas de agencia, que no solo deben estudiarse descriptiva y analíticamente desde el derecho, sino, también, desde el análisis económico del derecho. Pues dichos problemas de agencia son un factor categórico en la posible apertura de los procesos de reorganización o liquidación, siendo que deban ser tratados desde un enfoque de la eficiencia económica. Dentro de las dificultades económicas de las empresas, es ineludible reducir los inconvenientes de la agencia, como elemento determinante de aquellas. Los contratiempos de la agencia son clave en la generación de problemas económicos de las empresas y su posible ingreso a procesos de reorganización o liquidación, siendo que este hecho se puede evitar en virtud de la eficiencia económica.

\section{Palabras clave:}

Sociedades de capital concentrado, sociedades de capital difuso, problemas de la agencia, análisis económico del derecho y eficiencia económica.

\footnotetext{
* Este artículo es resultado del proyecto de investigación "Análisis económico del derecho comparado: activos intangibles y la protección de los acreedores en Francia y Colombia" adelantado en el Centro de Investigaciones de la Facultad de Derecho de la Universidad La Gran Colombia y está inscrito en el grupo de investigación Teoría del Derecho, de la Justicia y de la Política. Los autores agradecen el apoyo de la señora decana Dra. Gloria Inés Quiceno Franco y de los señores directores del Centro de Investigaciones Dr. Humberto Librado y Dr. Daniel Barragán de esta universidad.

* Abogado de la Universidad Libre. Sociólogo de la Universidad Nacional de Colombia. Magíster en Derecho Económico de la Universidad Externado de Colombia. Magíster en Derecho Comparado mención en Derecho Económico de la Universidad de París 1 Pantheón-Sorbonne. Docente de tiempo completo (asistente) de la Facultad de Derecho de la Universidad Militar Nueva Granada. Docente investigador de la Universidad La Gran Colombia. Profesor de posgrado de la Facultad de Jurisprudencia de la Universidad del Rosario. Correo electrónico: Jfrank1980@gmail.com

*** Egresado de la Universidad Libre. Monitor del Área de Derecho Público. Auxiliar de investigación en la misma universidad. Correo electrónico: jaimemanrique@yahoo.es
} 


\title{
THE CONSTITUTION AND THE PROBLEM OF THE AGENCY IN COMPANIES WITH CONCENTRATED CAPITAL FROM THE ECONOMIC ANALYSIS OF LAW
}

\begin{abstract}
Summary
Legal rules on corporate matters govern the structure of commercial corporations of concentrated capital and commercial corporations of diffuse capital, from which agency problems are derived, which should not only be studied in an analytical and descriptive way from the point of view of law, but also from an economic analysis of law. Therefore, these agency problems are a categorical factor in the potential opening of reorganization or liquidation processes, since these should be addressed from a perspective of economic efficiency. Among the economic difficulties of the companies, it is inevitable to reduce the issues of the agency, as a determinant element thereof. Setbacks of the agency are key in generating economic issues of the corporations and their possible entry to reorganization or liquidation processes, but this fact can be avoided by virtue of an economic efficiency.
\end{abstract}

\section{Keywords:}

Corporation of concentrated capital, corporations of diffuse capital, agency problems, economic analysis of law and economic efficiency.

\section{A CONSTITUIÇÃO E A PROBLEMÁTICA DA AGÊNCIA NAS SOCIEDADES DE CAPI- TAL CONCENTRADO DESDE O PONTO DE VISTA ECONÓMICO DO DIREITO}

\begin{abstract}
Resumo
As normas jurídicas, no que respeita à sociedade, regem a estrutura das sociedades comerciais de capital concentrado e das sociedades comerciais de capital difuso, das quais surgem problemas de agência, que não só devem ser estudados pelo direito a nivel descritivo e analítico, mas também económico. Esses problemas de agência são um factor categórico na possível abertura da reorganização ou liquidação, e devem ser abordados do ponto de vista da eficiência económica. Dentro das dificuldades económicas das empresas é factor inevitável reduzir os inconvenientes da agência. Os contratempos da agência são ponto chave na criação de problemas económicos para as empresas e também a sua possível entrada para recuperação ou liquidação, podendo tudo ser evitado sob eficiência económica.
\end{abstract}

\section{Palavras-chave:}

Empresas de capital concentrado, sociedades de capital difuso, problemas de agência, análise do direito e eficiência económica.

\section{A. Introducción}

No es suficiente estudiar el derecho desde adentro, esto es, como la estructura de un edifico (positivis- mo), como un sistema evaluador fundamentado en valores supremos (iusnaturalismo), como un conjunto dinámico y flexible de instrumentos aplicables a la realidad social (realismo jurídi- 
co) o, como un argumento que se organiza y desarrolla mediante la confrontación dialéctica (Atienza, 1999). Por el contrario, cuando se da un paso atrás y fuera del derecho, este toma la posición de objeto de estudio. En esta postura el análisis se puede efectuar desde afuera por la sociología, la antropología, la economía, entre otras ciencias.

Entonces, desde la economía se debe estudiar el derecho como objeto del criterio de eficiencia económica, toda vez que el análisis del derecho pertenece a un marco dinámico y no estático (Kirat y Marty, 2012). Por ello, en uso de las herramientas económicas se realiza un análisis del derecho (Cooter y Ulen, 2002), corriente conocida como law and economics o economics analysis of law (EAL).

El análisis económico del derecho (AED) es una disciplina que estudia el derecho (como objeto) capaz de buscar la producción de eficiencia económica, utilidad e incentivos para el crecimiento económico de las naciones. Es decir, que desde el criterio de eficiencia económica, ya definido por esta disciplina (AED), la estructura jurídica debe tener un norte o tendencia hacia la generación de incentivos para individuos que toman decisiones desde la elección racional (Posner, 2007). Entonces, la eficiencia económica es aquella en la que un medio es idóneo para maximizar la utilidad -en todos los aspectos de la vida, no solo el económico y reducir los costos.

Las normas jurídicas son las que deben considerarse como un medio idóneo para producir eficiencia económica dentro de la elección racional de los individuos. Por un mejor decir, los individuos por elección racional (buscan maximizar su utilidad y reducir sus costos) tomarán los medios que estimen idóneos (normas jurídicas con tendencia a la eficiencia económica) para lograr la satisfacción del interés individual, pero contribuirán, así mismo por comunidad de objetivos, al interés general (la búsqueda y obtención de objetivos individuales, mediante intereses individuales y comunitarios conjuntos, generan la búsqueda y obtención de objetivos generales).
El interés individual que se persigue, para este escrito, es aquel en el que se pueda evidenciar un crecimiento microeconómico mediante la constitución de sociedades comerciales y el desarrollo de su fin social, en reducción de los problemas de la agencia que de ellas se desprenden. Así, este crecimiento económico mediante la constitución de sociedades comerciales y la reducción de problemas de agencia que puedan surgir desde el derecho, inevitablemente forjará un efecto multiplicador sobre la economía y la sociedad, esto es, un espectro macroeconómico, para contribuir al interés general.

Entonces, la dificultad reside en las sociedades en cuanto a su estructura: aquellos problemas $\mathrm{de}$ agencia que se presentan en sociedades comerciales de capital concentrado y sociedades comerciales de capital difuso. Problemas que desde el AED son perceptiblemente solucionables, al regular de forma eficiente su desarrollo económico. Esto constituiría el estudio de una forma específica del AED, conocido como el AED societario, en concreto respecto del problema de la agencia.

Por tanto, el problema objeto de reflexión en este escrito es determinar aquellos escollos de agencia que sufren, en su regulación jurídica, las sociedades de capital concentrado y las sociedades de capital difuso, con el fin de establecer la eficiencia económica de estas normas jurídicas regulatorias de la materia, desde la perspectiva del AED. Siendo que el enfoque metodológico atiende a lo descriptivo, analítico, inductivo y de marco reflexivo. Pues se pretendió delimitar, de manera descriptiva, los preceptos que reglan las sociedades de capital concentrado y capital difuso, para así examinar dichas disposiciones legales y buscar los problemas de la agencia que se presentan en estas sociedades, e indagar sobre la posibilidad de mejorar la eficiencia económica que se pueda lograr, al encontrar las fallas de regulación jurídica. La exploración del derecho a través de las ciencias económicas requiere de la descripción de dichas normas jurídicas, análisis y aplicación de las herramientas económicas a las mismas. 
Ahora, en la aplicación de este enfoque metodológico al problema científico planteado, se obtuvo un conocimiento de cuáles son los presupuestos jurídicos que rigen la regulación de las sociedades de capital concentrado y las sociedades de capital difuso, encontrando la existencia de dificultades de agencia entre administradores y accionistas y entre socios mayoritarios y socios minoritarios. Que dichos problemas vistos desde el AED, en particular desde la eficiencia económica se traducen en la búsqueda de maximización de las utilidades y reducción al máximo de los costos por parte de los intervinientes en la sociedad (socios, accionistas o administradores). Sin olvidar que la discusión científica se centra, por ahora, en definir si se debe realizar una mayor o menor regulación jurídica que reprima o libere los intereses individuales y racionales de los socios minoritarios, socios mayoritarios o administradores, en cada caso, conforme con si es una sociedad de capital concentrado o una sociedad de capital difuso.

Este documento tendrá una presentación metodológica que orientó la investigación y, ahora, guiará al lector en su recorrido, para de esta forma informar sobre los resultados que se desprendieron de dicho ejercicio. Tal proceso metodológico comprende un estudio y lectura deductiva, iniciando por establecer el marco teórico-general del law and economics y las herramientas económicas de aplicación al derecho como objeto de estudio. Seguidamente, se identifican los problemas de la agencia en aplicación del referido AED, al igual que la caracterización de la agencia. Por último, se realiza un acápite de conclusiones en la que se exponen los resultados y síntesis de los análisis hechos a lo largo del texto.

\section{B. Marco genérico del análisis económico del derecho}

El AED se enmarca en el desarrollo de diferentes corrientes: la Escuela de Chicago, la Escuela del New Haven y la Escuela de la Nueva Economía Institucional (Núñez, 2000; Pinzón, 2010). Sin embargo, para no sumergirse en las teorías de las escuelas del AED, objeto de trabajos científicos ajenos (Franco, 2011; Mercuro y Medema, 1997) es procedente efectuar una conceptualización general sobre: qué es el AED desde la racionalidad y cuáles son sus instrumentos o metodologías de análisis, en especial la eficiencia económica.

En este orden de ideas, law and economics es una disciplina "qu'appliquer méthodes et cadres conceptuels à l'étude du droit ou des effets économiques des règles juridiques" (Kirat, 1999, p. 3). Por tanto, las herramientas económicas se aplican al estudio de las normas jurídicas, en procura de la eficiencia. Son las normas jurídicas y sus efectos económicos lo que estudia y evalúa esta disciplina. Pues los incentivos que se generan de forma jurídica son los puntos de referencia que tendrán los individuos en su elección. Elección que implica racionalmente la maximización de utilidad y la reducción, al máximo, de los costos.

Este uso que se hace de la eficiencia mediante incentivos jurídicos puede ser ejercido por individuos o por sociedades, es decir, por personas naturales o jurídicas. Pero estas últimas, la realizan de forma aparenten el mundo jurídico, puesto que el individuo -persona natural- es el único dotado con racionalidad (Descartes, 2037 y, en específico, de elección racional. Esto es, que las personas jurídicas están constituidas por personas naturales, que en últimas son quienes toman las elecciones y decisiones sociales.

Es ineludible pensar en la aplicación de los instrumentos económicos experimentales a las normas jurídicas, cuando existe la posibilidad de generar eficiencia y análisis para la comprensión y crecimiento; en diferentes aspectos de la vida: económicos, cognitivos, sociales, culturales y de políticas públicas. Es por esto que el AED se define como

[...] la aplicación de las teorías y métodos empíricos de la economía a las instituciones fundamentales del sistema jurídico, tales como: las doctrinas del common law sobre la culpa, los contratos y la propiedad; la teoría y la práctica de la pena; el procedimiento civil, penal y administrativo; la teoría de la legislación y de la producción normativa, 
y el cumplimiento forzoso del derecho y la administración judicial (Posner, 2007, p. 25).

Por tanto, el AED es una disciplina que permite el estudio de las normas jurídicas y, además, de los posibles comportamientos futuros que puedan tener los individuos de una sociedad. En este sentido, cabe la posibilidad general de anticipar los comportamientos y poder regularlos, en búsqueda de que el derecho se acerque mucho más a la regulación de comportamientos individuales y sociales que surgen de la dinámica social, económica, política y cultural. En otras palabras,

[...] en nuestros días law and economics puede ser definido como la aplicación de la teoría económica (principalmente de la microeconomía y de la economía del bienestar) al estudio de la formación, estructura, el proceso y el impacto económico del derecho y de las instituciones jurídicas (Mercuro y Medema, 1997, p. 3).

Esta es una explicación mucho más amplia respecto de la dada por el profesor Posner. En este sentido, no son concepciones contrarias sino complementarias en un desarrollo posterior (Kirat y Marty, 2012).

Entonces, el derecho y la economía tienen una relación coherentemente proporcional, alejando los demás factores, en razón de la administración de los recursos escasos en búsqueda de la satisfacción, en la mayor medida de las posibilidades, de las necesidades. Un vínculo directo, positivo y eficiente entre el derecho y el mercado que maximiza la utilidad o bienestar (Malloy, 2000). Es decir, la naturaleza del razonamiento económico pertenece a una ciencia de elección racional en un mundo de recursos limitados en cuanto a las necesidades humanas a satisfacer.

Esta razón responde a que los hombres racionalmente intentan aumentar su interés propio (Posner, 2007), mediante un posible contexto de la toma ordinariamente de decisiones racio- nales ${ }^{1}$. Por lo tanto, el hombre racionalmente trata de maximizar la utilidad (satisfacciones económicas y de todos los aspectos de la vida), en la administración de recursos limitados, al responder por incentivos, en su elección, dentro de los cuales está el derecho.

\section{Herramientas económicas}

La primera herramienta de aplicación en la economía o en el AED es el costo de oportunidad (Coase, 1960). El profesor Posner "dice que si las transacciones no cuestan nada, la asignación inicial de un derecho de propiedad no afectará el uso final de la propiedad" (2007, p. 31).

Este consiste en la negación que se hace evidente cuando un recurso es empleado por otro individuo, correlativamente en la negativa del uso posible que pueda hacer otro sujeto. En otros términos, es

[...] la noción del costo como un precio alternativo en el que se incurre en un solo costo cuando se le niega a alguien el uso de un recurso. Dado que puedo respirar cuanto aire desee sin privar a nadie de nada del aire que desee, nadie me pagará por renunciar a mi aire en su favor, de modo que el aire no tiene ningún costo (Posner, 2007, p. 29).

Se discrimina así la concepción del costo privado y del costo social. El primero es la redistribución por transferencia que se hace de la riqueza que posee un individuo a otro. Por ejemplo, el hombre rico que traslada parte de su dinero al hombre pobre. El costo social es la disminución de la riqueza social. Sin embargo, en este último concepto se puede determinar que la disminución de la riqueza individual puede ocasionar la disminución de la riqueza social. En sentido contrariamente proporcional, como cuando la

Hay quienes, por ejemplo Herbert Alexander Simon, aseguran que el individuo no siempre procura tomar las decisiones más óptimas, pues bien consideramos que en contextos de mercado y no mercado, especialmente en la regulación legislativa, sí se observa la determinación de la toma de una decisión óptima. 
elección racional en búsqueda de la eficiencia económica atiende al interés privado en relación contributiva al interés general.

Pero esto último debe ser complementario con la gravitación que tienen los recursos hacia una utilización de mayor valor por disposición voluntaria en el mercado. Es decir, que la eficiencia de los usos de los recursos, se evidencia cuando la reasignación no aumentaría sus valores. Esta misma, definida desde el sentido de o desde la concepción de Kaldor-Hicks para el control de la eficiencia en la distribución de la riqueza (Stringham, 2001). La economía no puede establecer si la distribución de la riqueza es buena o mala, justa o injusta, pero sí puede determinar si la redistribución es más costosa. Además, le corresponde al derecho, en parte, realizar estos cambios en función de la eficiencia.

La aplicación de las teorías económicas, en concreto de la microeconomía y la economía del bienestar, es el mecanismo del análisis de la formación, estructuración, procesos e impacto del derecho y de las instituciones jurídicas (Mercuro y Medema, 1997), disciplina definida como el AED. Teniendo presente que el derecho tiene el propósito de normativizar, es decir, formular prescripciones, establecer principios coherentes y lógicos de lo que debe ser o son las normas jurídicas, mientras que la economía pretende fijar hipótesis de las cuales se puedan ejecutar procesos deductivos que orienten la explicación de los hechos que se observan y la determinación de patrones o regularidades (Pirou, 1939).

Entonces, una de las herramientas económicas que se aplican al derecho es la denominada eficiencia económica, que se alcanza cuando se implementa uno de sus factores determinantes como los costos de transacción. Dicha eficiencia económica consiste básicamente en que los individuos por ser racionales, poseen la facultad de tomar elecciones o decisiones de tipo racional; por ende, la elección racional está precedida por el supuesto de que las decisiones o elecciones de los individuos se toman en función de la maximización de su utilidad y la reducción al máximo de sus costos. En suma, el individuo toma decisiones racionales que se acompañan de la maximización de su utilidad y la reducción de sus costos en la obtención de aquella, allí se puede observar la aplicación de los costos de transacción que será nula, sino existen, en el empleo final del recurso, como ya se mencionó.

En este orden de ideas, la herramienta económica del AED: la eficiencia económica, se implementa de modo deductivo a aspectos concretos del problema de la agencia en sociedades de capital concentrado o sociedades de capital difuso. Es decir, las normas jurídicas realizan la regulación de las sociedades comerciales, dentro de las cuales surgen problemas de agencia que pueden estudiarse desde la eficiencia económica; esto es, se entiende que las normas jurídicas actúan como incentivos legales en la toma de decisiones racionales por parte de los individuos que direccionan sociedades comerciales en las que surgen problemas de agencia y además que en la creación (normas jurídicas) se busque la reducción de los costos de transacción. Ahora bien, sería execrable implicar el análisis económico de particularidades jurídicas, como son los problemas de la agencia en sociedades comerciales de capital concentrado y sociedades comerciales de capital difuso.

\section{El problema de la agencia}

En este estudio de la economía hacia el derecho, son determinables criterios primarios para el desarrollo lógico de los razonamientos que se deben llevar a cabo desde el AED. Estos criterios primarios son descritos así: a) en un contexto de mercado y no mercado, mediante el uso de la racionalidad, los individuos tienden a maximizar o aumentar la utilidad. En otras palabras, este presupuesto es conocido por Posner (2007), como el primer supuesto de la elección racional; b) en situaciones o contextos de mercado los incentivos para el individuo son los precios y en escenarios de no mercado los incentivos son las normas jurídicas o incentivos legales; y c) el criterio de eficiencia económica es el criterio transversal de evaluación del sistema u ordenamiento jurídico, 
que procura maximizar la utilidad y reducir los costos (Rubio, 2007). Así, el presente estudio general, que busca abrir un debate más amplio, toma las anteriores premisas para el análisis de las sociedades de capital concentrado y las sociedades de capital difuso.

Entonces, los individuos racionales pretenden la maximización de la utilidad mediante el uso de incentivos en contextos de mercado y no mercado, siendo así que el proceso de formación, formulación, estructuración, aplicación y exigibilidad de las normas jurídicas atiende a un criterio de eficiencia económica.

Ahora, esta eficiencia económica es notable en los preceptos jurídicos reguladores de la creación, funcionamiento, estructuración, modificación, insolvencia, reestructuración y hasta fusión de sociedades, en razón a que el empresario intenta obtener mayores rentabilidades correlativamente con los pocos costos, en términos de recursos, que quisiera invertir. Entonces, es aquí cuando el derecho es instrumento que incentiva o no, el comportamiento del empresario. A este tipo de análisis, entre otros, se le ha llamado AED societario, localmente representado por Reyes (2012).

Es así como se señala que se debe estudiar a través de instrumentos económicos los regímenes societarios vigentes para su comprensión y restablecimiento -civil law- (Reyes \& Vermeul, 2011). En este sentido, el AED societario se presenta en los contextos de no mercado en donde los incentivos de elección de los individuos racionales se motivan por las normas jurídicas societarias que les son favorables, en cuanto maximizan su utilidad y reducen sus costos, como la disminución de los costos de transacción, la flexibilidad en la constitución de sociedades, la limitación de la responsabilidad societaria, la efectividad de la función jurisdiccional, la organización autónoma de sus órganos fundacionales y administrativos, etc.

Por tanto, veamos las sociedades de capital concentrado y las sociedades de capital difuso, al igual que el modo en que surgen los problemas de agencia desde un espectro de la eficiencia económica en el AED, siendo este un escenario de no mercado que estimula a los actores en función de las normas jurídicas que les son más eficientes económicamente.

\section{Sociedades de capital concentrado y capital disperso}

En las sociedades participan intereses individuales que pueden o no confluir en un interés común social que permita su desarrollo, dichos intereses se concretan en lo que racionalmente cada uno de sus agentes demuestre frente a la sociedad y sus demás agentes. Tales intereses pueden presentarse en socios y administradores al interior de sociedades de capital concentrado y capital disperso.

En una ecuación sencilla, para esta investigación, podría mencionarse que los propietarios $(\mathrm{P})$ y los administradores (A) son la totalidad de la sociedad de capital disperso ( $\mathrm{Sd}$ ), dejando de lado al trabajador y otros actores que intervienen allí. Pues es pertinente desarrollar inductivamente y a manera de experimento un análisis de los problemas de la agencia en las sociedades. Entonces, tenemos que $\mathrm{P}+\mathrm{A}=\mathrm{Sd}$.

Por otro lado, se tiene que los propietarios mayoritarios (PM) más los propietarios minoritarios (Pm) es igual a la sociedad de capital concentrado (Sc): $\mathrm{PM}+\mathrm{Pm}=\mathrm{Sc}$. Así se observa cómo unas sociedades pueden estar constituidas por socios y administradores y otras por socios mayoritarios y socios minoritarios. Hasta aquí, se puede definir de manera simple las denominadas sociedades de capital disperso y las sociedades de capital concentrado, respectivamente. En este sentido, las sociedades se conforman por individuosque tienen una posición racional y económica diferente, sea los administradores o los propietarios (mayoritarios o minoritarios), atendiendo conforme con sus intereses individuales, posiblemente dentro de un marco de intereses comunes y sociales. 
Cada uno de los participantes dentro del marco de una sociedad de capital concentrado o sociedades de capital disperso (socios -minoritarios y mayoritarios- y administradores), busca un interés privado o individual a satisfacer. Por lo que la suma de los intereses individuales genera el interés social común. Pero esos intereses tienen un origen o causa: los incentivos. Incentivos que como se dijo pueden ser de mercado y de no mercado. En el escenario de no mercado se encuentran como incentivos las normas jurídicas. Siendo que si los incentivos legales son el origen y determinación de los mismos intereses en propietarios - minoritarios y mayoritarios- $y$ administradores, la sociedad será una totalidad en función de un interés común equilibrado. Interés común que tenderá a satisfacer intereses de participantes en la actividad social y sus repercusiones.

Se entiende entonces que los incentivos forman o deforman los intereses (individuales y/o comunes). En especial aquellos que provienen de un contexto de no mercado, normas jurídicas, pueden dar lugar a la formación y unificación de intereses de los participantes en las sociedades mencionadas o pueden dar lugar a la deformación de dichos intereses en detrimento de las citadas sociedades. Pues en suma, las sociedades y, en particular, las sociedades de capital concentrado y las sociedades de capital disperso son un conjunto de intereses individuales.

Teniendo presente que los intereses son un elemento determinante en la constitución y desarrollo de las sociedades, de capital disperso y concentrado, desde el AED societario son de estudio la formación social y económica de tales sociedades comerciales, lo cual se hará un poco más detallado, considerando la predisposición de intereses que participan al interior de dichas sociedades.

En este hilo conductor, se entiende que las sociedades se pueden estructurar en su dirección y capital formativo por ejemplo: a) en propietarios mayoritarios y propietarios minoritarios o; b) en propietarios diversos y administradores. Sistemas que se reconocen por ser de capital concentrado o capital disperso (Reyes, 2012). Clasificación que es necesario describir, a grandes rasgos, para poder entender la conceptualización de los sistemas de sociedades de capital concentrado y las sociedades de capital disperso.

Como ya se dijo, al interior de las sociedades comerciales se establecen relaciones jurídicas distintas que permiten caracterizarlas, así: a) sociedad comercial de capital concentrado se constituye por propietarios o socios mayoritarios y minoritarios, sean un conjunto de cada uno de ellos o una individualidad; y b) sociedades comerciales de capital disperso con socios o accionistas y administradores, sean un conjunto o individualidad de cada uno de ellos. El profesor Francisco Reyes Villamizar (2012) lo expone, a manera de síntesis, tal como muestra la tabla 1.

\section{Tabla 1.}

\begin{tabular}{|l|l|}
\hline $\begin{array}{c}\text { Mandante - Cumple } \\
\text { funciones }\end{array}$ & $\begin{array}{c}\text { Los costos de la agencia } \\
\text { - términos de costos }\end{array}$ \\
\hline Accionistas & Administrador \\
\hline Accionistas minoritarios & Accionistas mauoritarios \\
\hline Otros ineresados & La sociedad \\
\hline
\end{tabular}

Fuente: Reyes (2010)

Las sociedades de capital disperso son aquellas formadas ordinariamente por diversos y gran cantidad de socios o accionistas y administradores. Determinan de forma clara y precisa la discriminación de los derechos de propiedad y el ejercicio del control administrativo. En otras palabras, son propietarios y ejercen todos sus atributos, los socios o accionistas y son administradores aquellos que ostentan el control de la empresa orientando su destino, ejerciendo una función administrativa (Gonzales, 2008).

La empresa debe estar dirigida por el individuo que toma las decisiones racionalmente para poder actuar en el mercado (Gonzales, 2008); esto es, el administrador en una sociedad de capital disperso. Modelo que es propio de paí- 
ses anglosajones como Estados Unidos y Gran Bretaña, donde la legislación se preocupa, desde el objeto de las normas jurídicas societarias, en regular las relaciones entre socios y administradores (Reyes, 2012).

Por otro lado, el modelo de las sociedades de capital concentrado, regularmente hallado en Europa continental y en particular en Francia, sin perjuicio de las raíces locales (Reyes, 2010), se destacada por una gran concentración de propiedad, donde existen accionistas mayoritarios y minoritarios. Pero en cuanto al control y administración, estos los ejercen los accionistas mayoritarios, los cuales son unos pocos accionistas con derecho de dominio sobre el $50 \%$ o más de las acciones en circulación (Reyes, 2012). Para Reyes:

Tal es el caso de América Latina, donde el alto nivel de concentración de capital implica que el control sea ejercido con exclusividad por los accionistas mayoritarios. Se ha sostenido en efecto que, como resultado de la estructura de capital en las sociedades latinoamericanas, el aspecto central en los regímenes societarios de esta región es la posible divergencia de intereses entre los accionistas mayoritarios y los minoritarios [...].

[...] Una primera conclusión del análisis económico del derecho societario en América Latina consiste en la necesidad de tener en cuenta el modelo de capital concentrado que prevalece en la región, con el propósito de formular políticas legislativas que correspondan a la estructura de capital dominante en los mercados de la región, por lo que los regímenes jurídicos latinoamericanos podrían enfocarse con mayor propiedad en el problema de agencia que se origina en el conflicto existente entre los accionistas mayoritarios y minoritarios (2012, p. 43).

Las sociedades de capital concentrado son aquellas predominantes en la práctica y en la regulación societaria para nuestra región, pero no obsta para que no se observen las sociedades de capital disperso, pues en unas y en otras se dan problemas de agencia. Esto es, a grandes rasgos, que los conjuntos que pueden llegarse a presentar, sea de socios mayoritarios y socios minoritarios o de socios y administradores, en el manejo o direccionamiento de la sociedad pueden llegar a evidenciar, por diversos intereses, conflictos de agencia ${ }^{2}$.

Ahora a manera de ejemplo, para el caso colombiano, en donde se aplica el modelo de las sociedades comerciales de capital concentrado ${ }^{3}$, es predominante la regulación, por objeto de las normas jurídicas, de las relaciones jurídicas entre socios mayoritarios y socios minoritarios. La prueba que confirma lo anterior, sobre la predominancia de un modelo de sociedades comerciales de capital concentrado, son las disposiciones legales de los artículos 43 y 44 de la ley 1258/2008, que norman los vínculos jurídicos entre los socios de una sociedad comercial por acciones simplificada.

No puede dejarse de mencionar que las sociedades por acción simplificada (SAS), se han trasplantado a Colombia de forma adecuada -en búsqueda de eficiencia económica- de Estados Unidos y Francia por el jurista colombiano Francisco Reyes Villamizar. Este tipo de sociedades se caracterizan por ser: a) internacional, que consiste en que las formas societarias jurídicas sean iguales para aquellos locales e inversionistas extranjeros en Latinoamérica; b) tener

2 El problema de la agencia se establece en cuanto a la sociedad y la administración. Sin embargo, en las sociedades de capital concentrado, socios mayoritarios y socios minoritarios, al ser aquellos los que ostenten la administración se generan problemas de agencia frente a los minoritarios. Esto se evidencia en el caso de que los socios mayoritarios en administración de la sociedad toman decisiones, posiblemente su posición decisoria dominante, en detrimento de los intereses de los socios minoritarios. Esto último, conlleva con probabilidad, que los socios minoritarios abusen de sus derechos sea para frenar, redireccionar o incluso lograr sus intereses mediante decisiones a su favor.

3 Esto no excluye el estudio de las sociedades de capital disperso, pues solo se toman por su mayor aplicación, desde el AED societario, el examen de las sociedades de capital concentrado predominante en la región. 
libertad de forma, esto es, que la autonomía de la voluntad gobierna las formas al alcance de los que pretenden constituir una sociedad, además, de que se encuentren en la posibilidad de elegir entre las formalidades más altas o bajas y los más modernos documentos electrónicos; c) esto dentro de un marco de la consensualidad ${ }^{4}$ de los negocios mercantiles, donde la mera voluntad de los contratantes los vincula jurídicamente; d) la desjudicialización, consistente en que los conflictos que surjan sean solucionados por jueces especializados -tribunales de arbitraje-; y e) la flexibilidad societaria en búsqueda de la eficiencia económica y la minimización de costos de transacción (Reyes, 2010).

Siguiendo con el ejemplo colombiano, se puede decir que la constitución de sociedades, específicamente de las SAS, genera que sean conformadas como sociedades de capital concentrado respecto de: a) quienes quieren constituir la sociedad actúan bajo la elección racional y, por tanto, prefieren crear sociedades de capital concentrado en procura de reducir los costos administrativos ${ }^{5} \mathrm{y}$, posiblemente, los costos y riesgos del manejo de la información societaria; b) la toma de decisiones consensuadas y mayoritarias en la administración de la sociedad, teniendo en cuenta que los socios mayoritarios en una sociedad de capital concentrado pueden ejercer de una u otra forma la administración de la misma: c) los bajos costos que representa la conformación autónoma de los órganos societarios; y d) la posibilidad de que al ser un socio mayoritario se tenga mayor poder

$4 \quad$ Entonces, una de las características es la consensualidad en la constitución de las SAS y la función jurisdiccional, para la solución de conflictos sociales, que le es determinable por los socios en su constitución. Dichos parámetros legales (arts. 43 y 44 de la ley 1258/2008) fijan en un marco general la teoría jurídica aplicable, que se relaciona con el abuso del derecho y el presupuesto para la atribución de facultades jurisdiccionales en determinación de los instrumentos aplicables para disolver los conflictos jurídicos que se presenten entre los socios o accionistas por su diversidad de intereses contrapuestos.

5 Los costos de la contratación de un administrador ajeno a la sociedad y la tercerización de la información social, al ser aquel quien participe de esta, que en principio solo poseen los socios. decisional, respecto del monto de la participación que se tiene al interior de la sociedad. Son varias las causas que llevan a la conformación de sociedades de capital concentrado, dichas sociedades, para el caso colombiano, pueden presentar problemas de agencia ${ }^{6}$.

Ahora, nos detendremos en mostrar por qué una sociedad de capital concentrado, que se forma para reducir los costos administrativos, puede ocasionar problemas de agencia en su interior. Pudiendo decir que la evaluación de la constitución de una sociedad es la reducción de costos de transacción en virtud de la función contratista de trabajo especializado y organizado para hacer que se determinen sociedades comerciales de capital concentrado, en la reducción de los costos administrativos, y en sociedades comerciales de capital difuso en los efectos y manejo eficiente que supere los costos de contratación administrativa.

Así, los costos de transacción en las sociedades son definitivos cuando el individuo racional que pretende ejercer o desarrollar una actividad económica, determina que es más costosa en términos de utilidad general (económicos, tiempo, operación, entre otros), y que realizar dicha actividad económica individualmente es más difícil que de forma asociada. Es decir, que por el principio de costo de oportunidad y distribución especializada de trabajo es más eficiente operar desde la constitución de una sociedad que individualmente.

La especialidad en el trabajo es la constante que permite realizar labores más eficientes. Esto es, la distribución laboral en especialidades. Esta sirve en las sociedades que deben cumplir con productividad compleja: actividades económicas que

$6 \quad$ Es claro que desde la ley 1258/2008 y la experiencia en materia de formación de sociedades comerciales predominan localmente las sociedades comerciales de capital concentrado. No solo por la regulación jurídica (teoría del abuso del derecho y facultad de atribución de la función jurisdiccional para problemas sociales), sino además, por la experiencia de los individuos que se remonta a su elección racional en la que buscarán maximizar su utilidad y reducir los costos en la formación de sociedades comerciales. 
requieren desempeños de trabajo específicos en diferentes áreas para completar un solo producto, servicio o resultado. Entonces, la organización de la sociedad consiste en la especialidad del trabajo para generar la contratación de empleados por cada área concreta. Por ejemplo la contratación puntual de trabajo de un administrador que direccionará la empresa hacia los objetivos comunes, siendo que los propietarios serán quienes delegarán el poder y organizarán la distribución, junto con el administrador, de los recursos para su uso eficiente en la materialización de los objetivos y actividades sociales.

Entonces la constitución de una sociedad implica la especialidad de trabajo, la contratación, la organización y la administración. Actividades que ocasionan costos en su realización pero que se pueden disminuir notablemente en la elección racional de operar con un esquema societario y no de modo individual. Es decir, que los costos de transacción son inferiores desde el esquema societario. La sociedad es viable cuando se reducen los costos de transacción altos que produce llevar a cabo la actividad económica de manera individual. En este sentido, los costos de transacción son aquellos en que

[...] debe incurrir el empresario para negociar exitosamente y en forma individual con cada uno de sus proveedores de bienes y servicios. A manera de síntesis puede señalarse que una de las justificaciones que Coase [la naturaleza de la empresa] le atribuye a la firma se encuentra, precisamente, en la posibilidad de reducir tales costos (Reyes, 2012, p. 48).

Por ende, se extrae que los individuos racionales no solamente formarán sociedades para reducir los diversos costos de transacción en virtud de la eficiencia económica, sino además que cuando ya se encuentran en la formación de la sociedad podrán racionalmente elegir realizar la constitución de una sociedad comercial de capital concentrado, pues es ilógico que no pretendan aminorar los costos de administración en los que pueden incurrir si eligiesen la constitución de una sociedad comercial de capital disperso.
Así, recuérdese que la eficiencia económica consiste en maximizar la utilidad en la medida en que los costos sean reducidos. Este es un punto identificable en el análisis y deducción respecto de la eficiencia económica, que favorece a los individuos mediante las sociedades comerciales de capital concentrado, dominantes por factores del ordenamiento jurídico societario, la experiencia y la búsqueda racional de superior utilidad y menores costos.

Por tanto, la eficiencia económica se evidencia al conformarse sociedades de capital concentrado para reducir, uno de tantos, costos de transacción en la contratación de trabajo especializado en la administración y control de la sociedad. Es decir, que el individuo mediante su elección racional de maximizar sus utilidades y reducir en lo posible sus costos al interior de un contexto de no mercado, mediante incentivos legales, decide formar una sociedad de capital concentrado para así disminuir los costos de contratación en trabajo especializado de administración de la sociedad. Siendo, que dicha elección racional de constitución de una sociedad esté incentivada, como se mencionó, por las normas jurídicas de derecho societario -en un escenario de no mercado- que no le restringen la posibilidad de conformar sociedades de capital concentrado en las que los administradores puedan llegar a ser las mayorías societarias.

En este sentido, no es menos cierto entonces que la toma decisiones -poder administrativo-por los socios mayoritarios en una sociedad comercial de capital concentrado, elude la constitución de la agencia en favor de administradores que cargarán un costo operativo más a las posibles utilidades sociales. Si bien la agencia comprendería la administración de la sociedad comercial, independientemente del sujeto (socios mayoritarios o administradores), producirá costos que pueden disminuirse cuando estamos frente a la toma de decisiones de los mismos socios mayoritarios.

Es decir, pueden determinarse costos, como la remuneración por actividades de administración, los perjuicios ocasionados por la divergencia de 
intereses entre administradores y socios y los costos de eventuales resoluciones de conflictos sociales, todo esto aun cuando conceptualmente la agencia sea un contrato en donde el mandatario deberá seguir la orientación dada por el mandante.

En otras palabras, que la agencia se puede presentar de manera evidente dentro de un contrato de mandato donde una parte, el administrador, debe seguir las orientaciones de la otra parte mandante, socios. Pero esta contratación de trabajo especializado en administración -agencia-, como se vio, puede obviarse para reducir costos y ser ejercida por los socios mayoritarios. En cuyo caso la agencia se presenta de manera estatutaria en donde quienes administran -socios mayoritariosson a su vez mandante, olvidando una parte de sus mandatarios, los socios minoritarios ${ }^{7}$.

En este sentido la formación de las sociedades se establece sobre la necesidad de existencia de sociedades comerciales con socios mayoritarios y minoritarios. Así, se puede afirmar que su configuración justifica la teoría del abuso del derecho frente a terceros o entre los socios mayoritarios y los minoritarios. En especial este último, los socios mayoritarios al ostentar la facultad decisoria respecto de la administración de la sociedad, en su posición dominante decisoria y la búsqueda de maximizar sus utilidades, frente a los socios minoritarios hace que los intereses de una y otra colegiatura sean diversos, e incluso opuestos, siendo que no sea posible llegar a acuerdos sobre la administración de la sociedad conforme con los intereses de una u otra parte.

\footnotetext{
Téngase en cuenta que la parte mandante dentro de una agencia sería el conjunto de los socios mayoritarios y los socios minoritarios y la parte mandataria serían los socios mayoritarios, sin embargo, se torna que esta última ostentará las dos condiciones. Por tanto, la parte minoritaria en búsqueda de sus intereses hará uso de sus derechos, adecuada o abusivamente, para que sean considerados a la hora de tomar decisiones. Dicha controversia sobre la administración de sociedad se convierte en problemas de agencia al interior de la sociedad de capital concentrado, que son parecidos a los problemas de agencia entre los socios y los administradores en una
} sociedad de capital disperso.
Los socios minoritarios en la búsqueda de maximizar sus utilidades al igual que los mayoritarios, pueden generar, mediante el uso abusivo de sus derechos societarios, la modificación, el retroceso, el freno o, aun, el logro de sus intereses en la toma de decisiones mayoritarias al interior de la sociedad. En síntesis, se presenta un problema de agencia en cuanto a los socios mayoritarios y los socios minoritarios en una sociedad de capital concentrado.

\section{La agencia}

La agencia es un contrato en el que se determinan para su existencia dos partes: socios o accionistas y la singularidad o pluralidad de administradores. En otras palabras, el contrato de agencia es aquel mediante el cual una parte mandante o mandantes (socios o accionistas) de un lado y del otro, mandatario o mandatarios (administrador/ es) de mutuo acuerdo, aceptan que el mandatario pueda dirigir, manejar, orientar, administrar, controlar y desarrollar el objeto social. Siendo el administrador, que combinando y en uso eficiente de los recursos sociales, quien gestiona la orientación para el desarrollo de la actividad económica propia de la sociedad. Actividades que en principio, se entienden por una orientación que obedece a intereses sociales y no a intereses privados. Es decir, que sus intereses deben ser coherentes o acordes con los intereses sociales de sus mandantes. Esto es, se superponen los intereses de sus mandantes sobre los intereses de su mandatario o agente (Reyes, 2012).

Dichos intereses responden a un incentivo que motiva una elección, decisión y acción racional. Entonces, teniendo de presente las consideraciones realizadas sobre: las sociedades comerciales de capital concentrado, disperso y el contrato de agencia, es preciso interpretar, analizar $e$ identificar el planteamiento de que desde las premisas expuestas en torno al AED societario, los administradores en contextos de no mercado se encuentran incentivados por las normas jurídicas (incentivos legales), que suscitarán un interés individual, y posiblemente social, que los impulsará a tomar decisiones racionales en favor de la eficiencia económica individual o 
social: maximizar la utilidad individual o social y disminuir los costos en los que se ha incurrido en la obtención de dicha utilidad social o individual.

En otros términos, las premisas o presupuestos son entendidos en la medida que: a) el individuo, regularmente, en la toma de decisiones usa un proceso racional y económico para lograr maximizar su utilidad, y b) su respuesta a la toma de decisiones es influenciada al interior del proceso racional mediante incentivos de carácter negativo o positivo, interno o externo y con orientación persuasiva, normativa o económica.

Los incentivos de orientación normativa son observados por el individuo a través de su proceso racional y económico siempre y cuando estos obedezcan al principio transversal de la eficiencia económica. Es decir, que dentro de múltiples opciones o posibilidades de elección, el incentivo normativo llegue a ser el medio idóneo para lograr maximizar utilidad y reducir costos dentro de la actividad económica que desarrolla. En últimas, el sujeto racional determinará la razón de idoneidad de elegir ese incentivo normativo y no otro tipo de incentivo. Dará entonces respuesta a la pregunta: ¿jpor qué ese incentivo y no otro?

En consecuencia, la conformación, estructuración, reforma y orientación de los ordenamientos jurídicos societarios deben supeditarse al criterio transversal de análisis de la eficiencia económica. Criterio evaluador y estructurador que no puede ser desplazado por quienes interpretan y aplican el derecho societario y, mucho menos, por los académicos o doctrinantes jurídicos que estudian los procesos evaluativos del derecho como objeto. "En este sentido Stephen Bainbridge afirma, que en la actualidad es virtualmente imposible encontrar trabajos académicos serios en el ámbito del derecho societario sin un punto de referencia en el análisis económico" (Reyes, 2012, p. 23).

Como hemos venido sosteniendo el AED observa la formación, reforma y supresión de incentivos normativos, pero también debe examinarse las relaciones jurídicas internas $y / o$ externas, directas y/o indirectas que se desarrollan en el marco de un esquema societario. Tanto los incentivos normativos como los diferentes tipos de relaciones jurídico-contractuales se encuentran sujetos a la necesidad de aplicación tajante del principio de eficiencia económica.

Así, pues, la compañía es una ficción legal que representa un conjunto complejo de relaciones contractuales entre todos los actores. Es decir que el sujeto societario no es un ente, sino, más bien, un nodo en el que confluyen contratos explícitos e implícitos mediante los cuales se establecen derechos y obligaciones entre todos los participantes (Reyes, 2012, p. 52).

Todos aquellos actores y relaciones que confluyen en la sociedad hacen que se mida la eficiencia económica en términos de reducción de los costos de transacción de administración, en virtud de la conformación de sociedades de capital concentrado para que sean los socios mayoritarios los que ostenten la facultad de administración social.

Lo anterior se sustenta en que esta serie de relaciones internas (socios o accionistas, administradores y empleados en general), externas (sociedad y terceros: acreedores, bancos, órganos del Estado y otras organizaciones), directas (socios y administradores) e indirectas (sociedad, intermediaria y trabajadores, aun cuando este tipo de intermediación genere un aumento en los costos de transacción) son causa de la autonomía de la voluntad, sin perjuicio de las normas jurídicas dispositivas societarias. En este sentido el derecho societario busca complementar la autonomía contractual y regular aquellas situaciones jurídicas no previstas en el vínculo contractual establecido de mutuo acuerdo. Pero dichas normas jurídicas deben procurar la eficiencia económica, como lo haría cualquier individuo en uso de autonomía de la voluntad. Es decir, poder desde su autonomía de la voluntad obtener una maximización de su utilidad y una reducción de costos al elegir normas jurídicas eficientes, como incentivo en la formación societaria.

Los diferentes modelos estructurales de las sociedades tratadas permiten crear, jurídicamente, un 
incentivo. Incentivo que está precedido necesariamente de una elección racional del individuo en razón a la eficiencia económica. Entonces, si los costos de transacción son aquellos en los que incurre la sociedad al configurar relaciones contractuales, en virtud de la minimización de estos costos y la maximización de la utilidad (mayor del objeto social) será el individuo racional quien elegirá y tomará una decisión respecto de un marco jurídico societario (en particular las sociedades de capital concentrado que favorecen la reducción de los costos de administración) más favorable a sus intereses.

[...] una de las ventajas que surge de la escogencia de la sociedad puede originarse en la reducción de los costos que apareja su estructura de organización. En el empresario individual realiza contratos con distintos proveedores por medio de negocios bilaterales para cuya celebración debe incurrir en altos costos de contratación (Reyes, 2012, p. 58).

Precisamente esta elección de esquema societario apareja la reducción de costos, como son los importes de administración, mediante la contratación de trabajo específico en esta disciplina. En suma, escoger un esquema societario, como la sociedad de capital concentrado, es una elección racional que realizan los individuos en cuanto dicho esquema les permite reducir costos y maximizar utilidad, como son los costos de administración ya mencionados.

Los costos de transacción no solo se ocasionan en la contratación que debe efectuarse para desarrollar la actividad económica (costos de administración), sino que a estos se añaden otros que se conectan con la información, ya referidos. Es decir, la nueva economía de la información en la que participan en el ámbito societario y comercial: el know how, good will, patentes comerciales $e$ industriales, secretos industriales, derechos de autor y en especial los derechos estructurales de organización comercial societaria. Este último, es aquel en que debe darse un valor económico a la estructura organizativa que posibilita en el ejercicio, eventual liquidación o enajenación de la sociedad comercial aumentar la riqueza de sus socios o accionistas. Pues las sociedades deben caracterizarse por la estructura organizativa que les facilita el desarrollo eficiente y eficaz de la actividad económica que sustenta su existencia, en específico el manejo de la información de la sociedad y sus actividades.

Como afirma Reyes (2012) para Posner y Bainbridge otros costos que se presentan son los que tienen que ver con la incertidumbre o falta de información que haga viable plantear hipótesis o probabilidades de realización ciertas. La incertidumbre es la insuficiencia total de información, información errónea o información parcial que causa el no poder predecir sucesos futuros en el marco de probabilidades realizables. En este sentido, un activo intangible considerable dentro de la sociedad comercial es su estructura.

Frente a lo dicho en cuanto a los costos administrativos y los costos de información, podríamos preguntarnos quién tiene mayor manejo y conocimiento de tal información. A dicha pregunta hay una posible afirmación, pues aunque se busque reducir los costos de administración, es precisamente este-el administrador-quien tiene el mayor conocimiento técnico y disciplinar del quehacer de la sociedad.

Entonces, la elección racional respecto de un esquema societario de capital concentrado que posibilita reducir los costos de administración, no solamente apareja dicha disminución sino que además se debe tener en cuenta los costos en el manejo o administración de la información que debe controlar el encargado de la administración. Es decir, que al elegir para maximizar la utilidad y reducir los costos de administración un esquema societario de capital concentrado, también se aminoran los costos posibles -riesgos- y el control de la información societaria, pues en definitiva en tal esquema quien administre la sociedad y maneje la información, que pueda permitir predicciones o proyecciones sociales, en su gran mayoría serán los socios mayoritarios, al ostentar estos la facultad decisoria. 
La estructura societaria como activo intangible susceptible de valorarse económicamente para aumentar el patrimonio societario, es considerada en la medida que se pueda determinar si corresponde a una sociedad comercial de capital concentrado. En razón a que teniendo la forma estructural quien administra especialmente y los demás que intervienen en las actividades de la sociedad (propietarios, socios o accionistas, trabajadores, acreedores y Estado) pueden establecer el comportamiento futuro más o menos definido. Pues la estructura más las actividades y la información sobre la sociedad comercial ayudan a conocer claramente probabilidades de comportamiento de la persona jurídica y de los costos que ocasionará en un marco de eficiencia económica.

Son la reducción de costos de administración, los costos del manejo, confidencialidad y conocimiento de la información societaria para la proyección de sus actividades económicas, comportamientos sociales, conflictos y modos o procedimientos de resolución, los que incentivan o no a los individuos racionales, con la premisa de reducir al máximo los posibles costos (tiempo, recursos, productividad, daños materiales y extrapatrimoniales):

[debido] a dos circunstancias específicas: 1) los conocidos problemas de la jurisdicción ordinaria y de los tribunales de arbitraje, cuya usual lentitud entorpece la aplicación de la teoría del abuso, en especial, por dificultades en la apreciación de las pruebas y 2) la consideración según la cual el abuso del derecho tan solo da lugar a una indemnización de perjuicios [...] (Reyes, 2009, p. 64).

Con este derrotero, podemos deducir que con reducir costos de información y de administración mediante una sociedad de capital concentrado, como se había manifestado, es posible que se observen problemas de agencia que comportan el uso abusivo del derecho de los socios minoritarios que buscan imponer sus intereses sobre los intereses propuestos por los socios mayoritarios, administradores y cuerpo colegiado que tiene poder decisorio.
Dichos conflictos, fundamentados en la teoría del abuso del derecho, conllevan que se deban solucionar mediante la función de administración de justicia por parte del Estado o por los tribunales arbitrales, conforme con las cláusulas de fundación societaria. Así, es ineludible comentar siquiera estos costos de administración de justicia en los que se puede llegar a incurrir, de manera indirecta, al seleccionar un esquema de sociedad de capital concentrado.

En este sentido, los costos que se puedan minimizar desde normas jurídicas eficientes económicamente que tratan la administración de justicia, como costos indirectos, son también de estudio de la jurisprudencia constitucional. Entonces, como bien se conoce, la Corte Constitucional es aquella que ejerce el control de constitucionalidad abstracto y concentrado. El tribunal constitucional en Colombia es quien se encarga de realizar el estudio constitucional de las disposiciones legales que expide el Parlamento. Esto es, que se entiende que la Corte Constitucional efectúa un control constitucional de la potestad legislativa de forma abstracta, general e impersonal, de acuerdo con el contenido de las disposiciones legales. Además, dicho control se considera concentrado toda vez que es una atribución exclusiva y privativa de esta Corte.

La Corte Constitucional también hace un control concreto en sala de revisión de tutelas: cuando se presenta un caso específico y se busca la protección de derechos a través de la acción de tutela, la Corte Constitucional mediante la facultad automática de selección y revisión de tutelas realiza un análisis sobre el caso concreto para establecer precedentes, aplicables en virtud del principio de igualdad. Por otro lado, dicho poder de resolución de casos concretos es de contenido difuso, en razón a que el tribunal constitucional no es el único que puede ejercer dicha atribución. Entonces, todos los jueces de la República son jueces de protección de derecho por medio de la acción de tutela.

Entendido esto, frente a los posibles problemas de agencia deducibles tenemos que por ejemplo, 
en sentencia C-510/1997, al declarar exequible el párrafo del artículo 148 de la ley 222/1995, dentro de los razonamientos de la Corte, esto es, en sus obiter dicta y ratio decidendi, se puede determinar que se alude a un cierto problema de agencia de forma no solo horizontal, como se ha estudiado, sino una dificultad de agencia de forma vertical (Corte Constitucional, sentencia C-510/1997). Se denomina así para poder entender que existe una verticalidad entre una sociedad y otra o entre entes que se desprende de una sociedad de forma vertical, sin dejar de ser la misma, por factores económicos, financieros, administrativos, operativos, logísticos y representativos.

En esta sentencia de constitucionalidad se declara que si se origina una filial respecto de una sociedad matriz, es posible que se suscite una subordinación administrativa que puede producir una serie de choques entre los intereses de los administradores de las filiales y entre los socios minoritarios y mayoritarios que ostenten la dirección, manejo o administración de la sociedad matriz en general. Recuérdese que la filial forma parte de la sociedad y que se vincula de manera directa administrativa, financiera y operativamente con la sociedad matriz. Problema de agencia que puede desestabilizar la autonomía de la sociedad matriz y/o subordinada en su administración, patrimonio y operación habitual. Pues los intereses de la sociedad matriz y de la filial pueden ser diversos o contrapuestos. Siendo así, un problema de agencia vertical en el que las divergencias se presentan en cuanto a la representación de los intereses de la matriz y filial de la sociedad.

Parafraseando al profesor Reyes (2014), se dice que al existir subordinación, se crea una pérdida de autonomía económica, financiera, administrativa y de decisión por parte de las sociedades filiales. Además, las decisiones de la compañía controlante repercuten en la afectación del patrimonio de la subordinada y pueden dar lugar a su responsabilidad. Es decir, que los intereses de la filial y de la matriz pueden generar problemas de administración, pero además se pueden producir mayores costos en los que pueda incurrir la sociedad matriz por responsabilidades que cause la filial. Pueden ser estos inconvenientes de agencia entre sociedad filial y matriz.

Tanto es esta relación de administración -problema de agencia-, entre matriz y filial, que la Corte Constitucional en sentencia SU-636/2003, entiende como una circunstancia de control conjunto e intenso que pone a las matrices en una situación crítica, pues eliminó de forma temporal la responsabilidad subsidiaria de la sociedad controlante hasta que la jurisdicción en su especialidad ordinaria decida sobre este asunto de manera definitiva. La ausencia de valoración o examen de la administración de las matrices genera incertidumbre frente a su responsabilidad limitada y respecto de las filiales (Corte Constitucional, sentencia SU-636/2006). Responsabilidad que de declararse perjudica a las sociedades matrices en cuanto a elevados costos de indemnización motivados por los problemas de agencia en administración vertical.

No es difícil entender que además de las dificultades de la agencia en las sociedades de capital concentrado puede surgir un inconveniente de la agencia en sentido vertical entre matrices y filiales. Problemas de agencia que desvirtúan la inmutabilidad de las relaciones entre accionistas mayoritarios y minoritarios y entre las matrices y las filiales, que sean administradas por mayorías y minorías.

En otros términos, los problemas de agencia, como se expuso, se generan: a) en sociedades de capital concentrado y en sociedades de capital disperso; b) que respecto de las sociedades de capital concentrado, estas se constituyen en virtud del principio de eficiencia económica que busca reducir los costos de administración y de manejo de la información societaria, mediante la elección racional incentivada por normas jurídicas societarias de esquemas societarios en contextos de no mercado; c) que indirectamente se pueden producir costos de solución de conflictos respecto de la administración de justicia sobre problemas de agencia ocasionados al interior de las sociedades, sea a través de una jurisdicción estatal o de arbitraje; y d) que los problemas de agencia 
presentes en la sociedad de capital concentrado no solo pueden darse en la sociedad matriz, sino también en las sociedades filiales.

En definitiva, el problema de la agencia en sociedades comerciales de capital concentrado y capital disperso o entre las filiales y las matrices, suscita una serie de costos de transacción, representados en la administración de las sociedades comerciales, de información y en la solución de los conflictos sociales. Sin embargo, como ya se mostró, los costos de transacción son mayores en las sociedades de capital disperso, toda vez que el contrato de agencia provoca unos gastos en la constitución y desarrollo de las funciones propias de los administradores, lo cual se vería reflejado, también, en los problemas agenciales entre la filial y la matriz. Por tanto, visto desde la eficiencia económica, puede dejarse establecido que los incentivos legales deben tener una orientación a la formación de sociedades comerciales con bajos costos de transacción y a problemas de la agencia, lo que obedece a la constitución de sociedades de capital concentrado.

\section{Conclusión}

En conclusión, estas estructuras societarias pueden tener diferentes valoraciones e impactos económicos al ser consideradas como un ordenamiento jurídico específico que estimula la formación de las sociedades comerciales, pues existe mediante un incentivo legal un impacto económico en la formación y desarrollo de actividades por parte de las sociedades comerciales, ya sean de capital concentrado o de capital difuso. Pues también, elegirse racionalmente, de acuerdo con las condiciones, las más adecuadas para promover la eficiencia económica.

Estas estructuras societarias presentan conflictos de mandato, constituidos en ámbitos internos y externos: a) los intereses individuales hacen que los administradores y socios tengan desacuerdos en cuanto al direccionamiento de la sociedad, los administradores pueden o no imponer sus intereses sobre los de los socios o accionistas; b) en la sociedad de capital concentrado se evidencian problemas de agencia debido a los conflictos de intereses encontrados, entre socios mayoritarios y socios minoritarios, concentración de capital y poder en detrimento de las minorías, aun cuando estas dispongan de eventuales derechos de decisión. En ocasión estos derechos de las minorías se emplean para estancar o perjudicar las decisiones de las mayorías, teoría del abuso del derecho; c) otros problemas de agencia ${ }^{8}$ se pueden dar en un carácter vertical entre la sociedad matriz y la filial; y d) que los costos de transacción que incentivan a los individuos racionales para constituir sociedades de capital concentrado, pueden ser los de administración, información y, de manera indirecta, los declarados por responsabilidad de las actividades adelantadas por las sociedades filiales.

Con todo, las sociedades comerciales de capital concentrado o de capital difuso, al igual que las matrices y filiales, presentan problemas de la agencia que pueden causar costos de transacción (administración), costos en la resolución de conflictos societarios y costos en desarrollo de las decisiones tomadas, de esta forma es indispensable que sean las normas jurídicas societarias las promotoras de la eficiencia económica, como incentivo legal en un contexto de no mercado para individuos racionales. Los cuales toman decisiones de maximización de utilidad y reducción de costos, claro ejemplo en las sociedades de capital concentrado en las que la administración está a cargo de los socios mayoritarios. Contrario a las sociedades de capital disperso en donde la administración está a cargo de un administrador, al igual que el manejo de la información, caso en el cual se aumentan los costos de transacción.

Por tanto, en las sociedades de capital concentrado se disminuyen los costos de transacción, ya que no se requiere de la contratación de un administrador, pero es posible que se incrementen los costos en

8 Dentro de los problemas que podemos estimar como externos, están los suscitados entre los terceros, considerados mandatarios, y la sociedad, considerada mandataria, relación en la que se espera que esta última despliegue la actividad económica propuesta (objeto social). Véase Reyes $(2009,2012)$. 
la resolución de conflictos sociales, debido a la divergencia de intereses entre socios mayoritarios y minoritarios. En contraste con las sociedades de capital disperso en donde no solo se acrecentarán los costos de transacción, porque la administración de las sociedades deberá ser llevada por un administrador que debe contratarse específicamente para dicha tarea, sino que además a estos podrán sumarse los costos en la resolución de conflictos sociales en los contratos de agencia. Siendo una mejor elección racional para la eficiencia económica constituir sociedades de capital concentrado.

\section{Referencias}

Atienza, M. (1999). El derecho como argumentación. Disponible en: http://aulanet.umb. edu.co/aulanet_jh/archivos/22478/Tareas_UMB/ El_derecho_como_argumentacion.pdf

Coase, R. "The Problem of Social Cost". (1960) En The Journal of Law and Economics, (October). Vol. 03.The University of Chicago Press. Pp- 1-44.

Cooter, R. \& Ulen, T. (2002). Derecho y economía. México D. F.: Fondo de Cultura Económica.

Corte Constitucional. (1997). Sentencia C-510. Octubre 09 de 1997. M. P. José Gregorio Hernández Galindo.

Corte Constitucional. (2006). Sentencia SU-636. Julio 31 de 2003. M. P. Jaime Araujo Rentería.

Franco, J. F. (2011). Deontologismo y consecuencialismo: visiones y actuaciones de economistas y juristas. Bogotá: Universidad Libre.

Gonzales, I. C. (2008). Estudios de derecho y economía. Buenos Aires: Heliasta.

Kirat, T. (1999). Économie du droit. París: La Découverte, Collection Repères.

Kirat, T. \& Marty, F. (2012). Economía del derecho y de la regulación. Bogotá: Universidad Libre.

Malloy, R. (2000). Law and market economy. Cambridge: Cambridge University Press.
Mercuro, N. \& Medema, S. (1997). Economics and the law. From Posner to postmodernism. Princeton: Princeton University Press.

Núñez, A. J. (2000). Antecedentes y principios fundamentales del análisis económico de la ley. En: Colección de derecho económico. Homenaje a Enrique Low Murtra. Bogotá: Universidad Externado de Colombia.

Pinzón M. (2010). Aproximaciones al análisis económico del derecho. Bogotá: Universidad Externado de Colombia.

Pirou, G. (1939). Introducción al estudio de la economía política. París: Sirey.

Posner, R. A. (2007). Análisis económico del derecho. (2a edición). México D. F.: Fondo de Cultura Económica.

Descartes, R. (2001) El discurso del método (1637). Trad. Risieri Frondizi. Argentina: Alianza.

Reyes, F. (2010). SAS. La sociedad por acciones simplificada. Bogotá: Legis.

Reyes, F. (2012). Análisis económico del derecho societario. Bogotá: Pontificia Universidad Javeriana, Grupo Editorial Ibáñez, Grupo Bancolombia.

Reyes, F. (2014). El abuso de la personalidad jurídica de la sociedad. Bogotá: Universidad Externado de Colombia.

Reyes, F. \& Vermeulen, E. (2011). Company law, lawyers and "legal" innovation: common law versus civil law. Topics in Corporate Law \& Economics.Pp. 1- 34.

Rubio, M. (Colaboración: Ana María Arjona). (2007) Economía Jurídica: Introducción al Análisis Económico del Derecho Iberoamericano. Universidad Externado. Colombia.

Stringham, E. (2001). Kaldor-Hicks efficiency and the problem of central planning. The Quarterly Journal of Austrian Economics, 4(2), pp. 41-50. 